\title{
Holding our breath: the promise of tissue-resident memory T cells in lung cancer
}

\author{
Claire Marceaux $^{1,2}$, Clare E. Weeden ${ }^{1,2}$, Claire L. Gordon ${ }^{3,4}$, Marie-Liesse Asselin-Labat ${ }^{1,2,5}$ \\ ${ }^{1}$ Personalised Oncology Division, The Walter and Eliza Hall Institute of Medical Research, Parkville, Australia; ${ }^{2}$ Department of Medical Biology, \\ The University of Melbourne, Parkville, Australia; ${ }^{3}$ Department of Microbiology and Immunology, The Peter Doherty Institute, The University of \\ Melbourne, Parkville, Australia; ${ }^{4}$ Department of Infectious Diseases, Austin Health, Heidelberg, Australia; ${ }^{5}$ Cancer Early Detection and Advanced \\ Research Center, Knight Cancer Institute, Oregon Health and Science University, Portland, OR, USA \\ Contributions: (I) Conception and design: All authors; (II) Administrative support: C Marceaux, ML Asselin-Labat; (III) Provision of study materials \\ or patients: None; (IV) Collection and assembly of data: All authors; (V) Data analysis and interpretation: All authors; (VI) Manuscript writing: All \\ authors; (VII) Final approval of manuscript: All authors. \\ Correspondence to: Marie-Liesse Asselin-Labat. Personalised Oncology Division, The Walter and Eliza Hall Institute of Medical Research, 1G Royal \\ Parade, Parkville, VIC 3052, Australia. Email: labat@wehi.edu.au.
}

\begin{abstract}
T cell memory is critical in controlling infection and plays an important role in anti-tumor responses in solid cancers. While effector memory and central memory $\mathrm{T}$ cells circulate and patrol nonlymphoid and lymphoid organs respectively, tissue resident memory $T$ cells $\left(T_{R M}\right)$ permanently reside in tissues and provide local protective immune responses. In a number of solid tumors, tumor-specific $\mathrm{T}$ cell memory responses likely play an important role in keeping tumors in check, limiting cancer cell dissemination and reducing risk of relapse. In non-small cell lung cancer (NSCLC), a subset of tumor infiltrating lymphocytes (TILs) display phenotypic and functional characteristics associated with lung $T_{R M}$ ( $\mathrm{T}_{\mathrm{RM}}$-like TILs), including the expression of tissue-specific homing molecules and immune exhaustion markers. High infiltration of $\mathrm{T}_{\mathrm{RM}}$-like TILs correlates with better survival outcomes for lung cancer patients, indicating that $\mathrm{T}_{\mathrm{RM}}$-like TILs may contribute to anti-tumor responses. However, a number of $\mathrm{T}_{\mathrm{RM}}$-like TILs do not display tumor specificity and the exact role of $T_{\mathrm{RM}}$-like TILs in mediating anti-tumor response in lung cancer is unclear. Here we review the characteristics of $\mathrm{T}_{\mathrm{RM}}$-like TILs in lung cancer, the role these cells play in mediating anti-tumor immunity and the therapeutic implications of $\mathrm{T}_{\mathrm{RM}}$-like $\mathrm{TILs}$ in the use and development of immunotherapy for lung cancer.
\end{abstract}

Keywords: Tissue-resident memory T cells; immunotherapy; lung cancer; immunosurveillance

Submitted Jul 07, 2020. Accepted for publication Aug 10, 2020.

doi: $10.21037 /$ tlcr-20-819

View this article at: http://dx.doi.org/10.21037/tlcr-20-819

\section{Introduction}

The lungs are constantly exposed to pathogens throughout life and continually need to develop and maintain immunity against infection. T cell immunity is provided by central memory $\mathrm{T}$ cells $\left(\mathrm{T}_{\mathrm{CM}}\right)$, effector memory $T$ cells $\left(\mathrm{T}_{\mathrm{EM}}\right)$ and resident memory $\mathrm{T}$ cells $\left(\mathrm{T}_{\mathrm{RM}}\right)$ to enable rapid responses against re-infection. Each memory cell type has a distinct location: $\mathrm{T}_{\mathrm{CM}}$ are mostly present in secondary lymphoid organs and the circulation, $\mathrm{T}_{\mathrm{EM}}$ patrol the blood, transiently entering peripheral organs, and $T_{R M}$ permanently reside in most tissues such as the lung, gut, skin, brain and liver (1-4). $\mathrm{T}_{\mathrm{RM}}$ form a defensive barrier against viral and bacterial infections and have also emerged as an important population in regulating anti-tumor immunity $(5,6)$. High numbers of tumor infiltrating lymphocytes (TILs) that display a $\mathrm{CD} 103^{+} \mathrm{T}_{\mathrm{RM}}$-like phenotype in carcinomas have been associated with improved survival in multiple solid cancers (7-9). These $\mathrm{T}_{\mathrm{RM}}$-like cells likely play 
Table 1 Summary table depicting distinct characteristics of healthy lung $\mathrm{T}_{\mathrm{RM}}$ and $\mathrm{T}_{\mathrm{RM}}$-like tumor-infiltrating lymphocytes

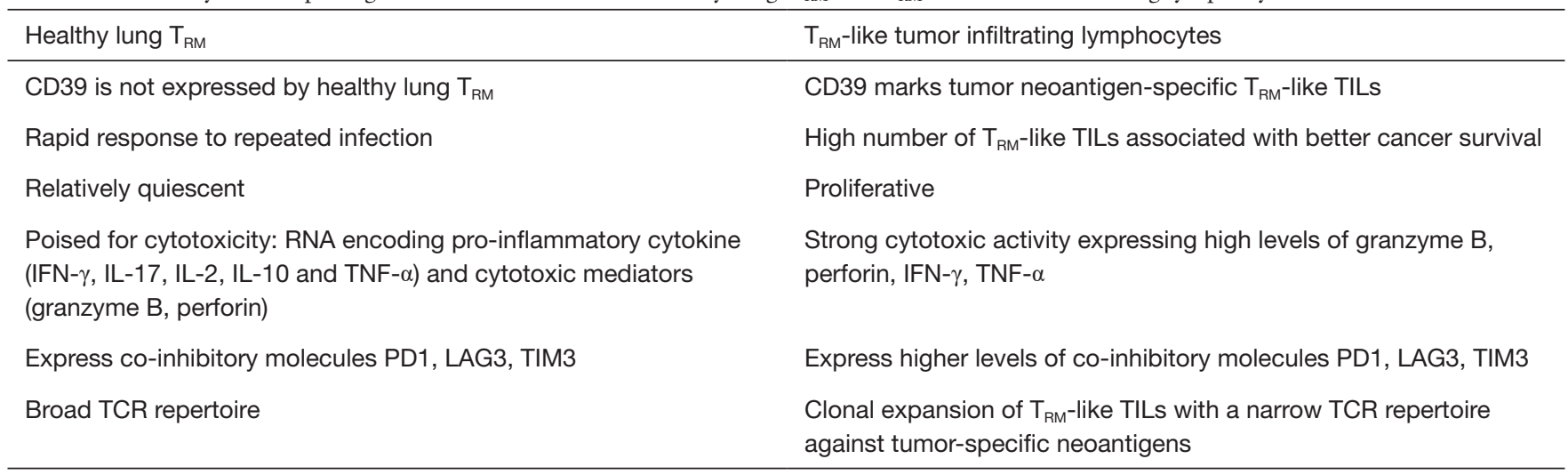

an important role in cancer immune surveillance and maintenance of a cancer-immune equilibrium in latent tumors before immune-escape mechanisms are developed by tumor cells and invasive tumors form (10). In lung cancer, vast diversity exists in both the abundance and composition of tumor-infiltrating cells, even between patients with the same tumor types (11). For the last few years, lung cancer research has focused on understanding the diverse immune populations infiltrating lung tumors with the overall aim of identifying the populations that play critical roles in anti-tumor immunity. There is now evidence that non-small cell lung cancer (NSCLC) TILs comprise not only tumor-specific $\mathrm{T}$ cells but also bystander $\mathrm{T}$ cells that do not have a T-cell receptor (TCR) specificity for tumor neoantigens, yet may still play a role in the overall cancer immune response (12). $\mathrm{T}_{\mathrm{RM}}$-like TILs appear to participate in anti-tumor immunity, either through direct cytotoxic activity (5) or by promoting the recruitment of functional activated cytotoxic $T$ cells to the tumor site (13), raising the possibility of targeting these cells for novel immunotherapies.

Despite the potential role for $\mathrm{T}_{\mathrm{RM}^{-}}$-like TILs in controlling lung cancer, several fundamental questions remain about the identification of $T_{R M}$ in cancerous lesions, how $\mathrm{T}_{\mathrm{RM}}$ function in healthy lung, and how they may protect against lung cancer spread. This knowledge is important for the design of strategies that manipulate antitumor $\mathrm{T}_{\mathrm{RM}}$ in lung cancer for potential immunotherapies. Here, we provide an overview of lung $\mathrm{T}_{\mathrm{RM}}$ in health and lung cancer (Table 1) and discuss how this crucial $\mathrm{T}$ cell subset may be harnessed in the development of lung cancer immunotherapies.

\section{Identification and phenotype of lung $T_{R M}$ in health and cancer}

Human $\mathrm{T}_{\mathrm{RM}}$ were first identified following HLAmismatched transplantation (14) and depletion of circulating memory $\mathrm{T}$ cells with anti-CD52 antibody studies (Alemtuzumab) (15), which demonstrated a population of tissue-resident cells in disequilibrium with the blood. These initial studies established CD69 and the integrin CD103 to be canonical markers associated with $T_{R M}(14,15)$. Further studies have elucidated markers specific to $T_{R M}$ and factors responsible for their maintenance [reviewed in $(16,17)$ ]. Like $\mathrm{T}_{\mathrm{EM}}, \mathrm{T}_{\mathrm{RM}}$ express the memory marker CD45RO, and do not express CD45RA, a marker of naïve $T$ cells and terminally differentiated effector memory $T$ cells $\left(T_{\text {EMRA }}\right)$, nor the lymph node homing marker CCR7 (18). $T_{R M}$ can be distinguished based on their expression of CD69, CD103 ${ }^{+/-}$ and $\mathrm{CD} 49 \mathrm{a}^{+-}$, although $\mathrm{T}_{\mathrm{RM}}$ that do not express these markers are likely to exist, as is found in mice (19). CD69 is a transmembrane C-Type lectin protein that prevents egress of $\mathrm{T}$ cell from tissues by interfering with the activity of the receptor for the bioactive lipid sphingosine-1 phosphate (20). CD103, or integrin alpha $\mathrm{E}$ (ITGAE) is induced by TCR engagement in the presence of transforming growth factor beta (TGF- $\beta)(21)$ and forms a complex with integrin beta 7 (ITGB7). This complex binds to e-cadherin present on epithelial cells to promote the intra-epithelial retention of $\mathrm{CD} 103^{+} \mathrm{T}_{\mathrm{RM}}$ (22). The majority of $\mathrm{CD}^{+}$mouse and human lung $T_{R M}$ express CD103, but CD103 is only expressed in less than a quarter of human $\mathrm{CD}^{+} \mathrm{T}_{\mathrm{RM}}$ and absent on mouse $\mathrm{CD}^{+} \mathrm{T}_{\mathrm{RM}}(19,23)$. CD49a [integrin alpha 1 (ITGA1)] and CD11a [integrin alpha $\mathrm{L}(I T G A L)$ ] are expressed by $\mathrm{CD}^{+}$and $\mathrm{CD}^{+} \mathrm{T}_{\mathrm{RM}}$ although the expression of CD11a appears restricted to alveolar $\mathrm{T}_{\mathrm{RM}}(23-28)$. These integrins 
are involved in cellular adhesion and costimulatory signaling, and CD11a is also required for $\mathrm{CD} 8^{+} \mathrm{T}$ cell entry in the lung parenchyma (29).

While CD103 and CD69 are commonly used markers of $T_{R M}$ in healthy tissues, relying on these markers to identify $T_{R M}$ in TILs may be problematic. The expression of CD103 can be induced on circulating $\mathrm{CD}^{+} \mathrm{T}$ cells in the presence of TGF- $\beta$ (30) which is secreted in the tumor microenvironment. CD69 is transiently expressed in response to antigen or inflammation, such that CD69expressing $\mathrm{T}$ cells in tissues may be activated and transiting through the tissue, but not resident (31). Nevertheless, multiple studies have now shown that TILs in NSCLC and other solid tumors display a phenotype reminiscent of $T_{\mathrm{RM}}$, describing them as $\mathrm{T}_{\mathrm{RM}}$-like cells $(5,6,8,32)$. In lung tumors, not all $\mathrm{CD} 69^{+} \mathrm{CD} 8^{+}$or $\mathrm{CD} 4^{+}$TILs express CD103 (6). While the number of $\mathrm{CD} 69^{+} \mathrm{CD} 103^{+} \mathrm{CD} 8^{+} \mathrm{T}$ cells increases in lung tumors compared with normal lung, $\mathrm{CD} 69^{+} \mathrm{CD} 103^{-}$ $\mathrm{CD}^{+}$are more prevalent in the tumor than in the normal lung, and are more abundant than $\mathrm{CD} 69^{+} \mathrm{CD} 103^{+} \mathrm{CD} 4^{+}$ TILs (6). The $T_{R M}$ pool in TILs therefore consists of diverse subsets of cells, with varying levels of expression of CD69 and CD103. CXCR6 and CD49a have also been shown to define $\mathrm{T}_{\mathrm{RM}}$-like TILs being expressed in both $\mathrm{CD} 9^{+} \mathrm{CD} 103^{+/-} \mathrm{CD} 4^{+}$and $\mathrm{CD} 69^{+} \mathrm{CD} 103^{+/-} \mathrm{CD} 8^{+}$TILs (6).

Insights into markers of tumor-specific $\mathrm{T}_{\mathrm{RM}}$-like cells has also come from the analysis of markers of $T_{R M}$ in chronic infectious diseases. CD39, a marker of exhausted $\mathrm{T}$ cells in patients with chronic viral infection was found to be expressed in tumor infiltrating $\mathrm{CD} 103^{+} \mathrm{CD} 8^{+}$ TILs in head and neck squamous cell carcinoma, lung, melanoma, ovarian, and colorectal cancer (32). CD39 is highly expressed in $\mathrm{CD} 103^{+} \mathrm{CD} 8^{+}$TILs compared with CD $103^{-} \mathrm{CD}^{+}$TILs in early stage NSCLC tumors (5). $\mathrm{CD} 39^{+} \mathrm{CD} 103^{+} \mathrm{CD} 8^{+} \mathrm{T}$ cells were also detected in metastatic lymph nodes, but not in non-tumor involved lymph node or the circulating blood, suggesting that CD39 is a marker of tumor-specific $\mathrm{T}_{\mathrm{RM}}$-like cells (32). CD39 is a cell surface ectonucleotidase that dephosphorylates ATP to AMP. Excess ATP can be toxic for cells, suggesting that CD39 expression by $\mathrm{CD} 103^{+} \mathrm{CD} 8^{+}$cells may be a way to protect $\mathrm{T}_{\mathrm{RM}}$-like TILs from ATP-induced cell death. CD39 may prove to be a critical marker to distinguish tumor neoantigen-specific $\mathrm{T}_{\mathrm{RM}}$-like TILs from other antigen-specific $\mathrm{T}_{\mathrm{RM}}$. Simoni et al. observed that in lung tumor and colorectal cancer, only $\mathrm{CD} 39^{+} \mathrm{CD} 8^{+}$TILs and not $\mathrm{CD} 39^{-} \mathrm{CD}^{+}$TILs had undergone neoantigen-driven clonal expansion (12). Analysis of 40 human lung cancer samples by mass cytometry revealed that a large portion of TILs were bystander CD8 ${ }^{+}$TILs that express CD103 and CD69 but did not express cancer-related epitopes (12). These bystander $\mathrm{CD}^{+} \mathrm{T}_{\mathrm{RM}^{-}}$-like TILs express coinhibitory molecules such as PD1, but do not express CD39. CD38, another ectonucleotidase that also regulates adenosine signaling, was found highly expressed in NSCLC CD103 TILs further suggesting that regulation of the adenosine pathway may be an important mechanism for tumor-specific $\mathrm{T}_{\mathrm{RM}}(5)$.

Further insight in the heterogeneity and distinguishing features of cancer $T_{\mathrm{RM}}$-like TILs compared to healthy tissue $T_{R M}$ will come from the use of novel single cell technologies including single cell RNA sequencing (scRNAseq), cytometry-based assays including mass cytometry (CyTOF), CITE-seq, and multi-parametric immunostaining technics. Single cell RNAseq analysis of lung CD $103^{+}$ TILs compared with non-malignant tissue $\mathrm{CD} 103^{+} \mathrm{T}$ cells has revealed greater activation of these $\mathrm{T}_{\mathrm{RM}}$-like cells in NSCLCs, where the protein expression of additional cell surface markers could further clarify the heterogeneity and tumor-specificity of $\mathrm{T}_{\mathrm{RM}}$-like TILs (33). High parameter mass cytometry experiments (34), or CITE-seq that takes advantage of DNA-barcoded antibodies combined with scRNA sequencing (35) constitutes novel technologies to explore distinct features of $\mathrm{T}_{\mathrm{RM}}$ in cancer and healthy tissue from the same organ. Multi-parameter immunostaining methodologies in tissue would also complement these approaches to provide in depth information on the spatial organization of these cell types (36).

\section{Localization and regulation of lung $\mathbf{T}_{\mathrm{RM}}$}

The location and turnover of lung $\mathrm{T}_{\mathrm{RM}}$ is tightly controlled to ensure rapid defense against infection while preserving tissue integrity. Lung $T_{R M}$ are localized in two different compartments in the human and mouse lung: the lung parenchyma or alveolar region, and the airways (bronchi and bronchioles) (24,28,37-40). Studies analyzing the precise localization of $T_{R M}$ have been conducted in the mouse lung following influenza infection $(41,42)$. A month after flu infection, $\mathrm{CD} 4^{+} \mathrm{T}_{\mathrm{RM}}$ were found clustered in a niche surrounding the mouse airways, in proximity to the primary site of reinfection, consistent with their helper $\mathrm{T}$ cell role (28). In contrast, $\mathrm{CD} 8^{+} \mathrm{T}_{\mathrm{RM}}$ did not form clusters and were detected within the epithelial repair region in the parenchyma and peribronchial area (25) (Figure 1A). In the human lung, $\mathrm{CD}^{+}$and $\mathrm{CD} 8^{+} \mathrm{T}_{\mathrm{RM}}$ are detected in both the 
A

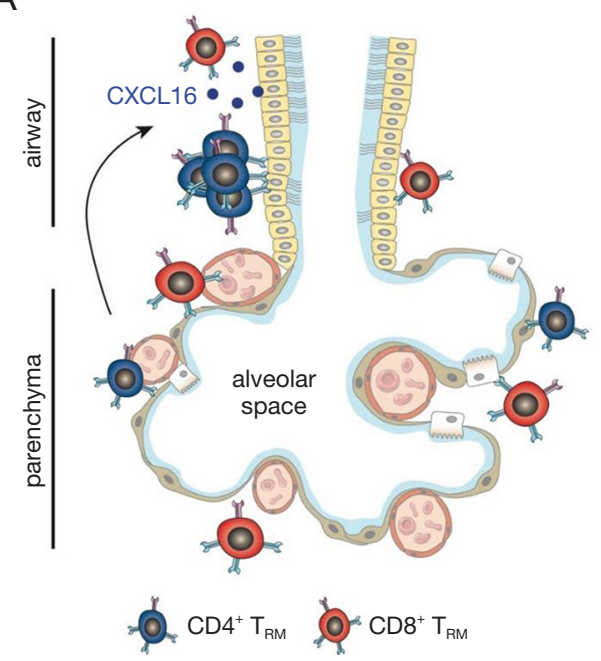

B

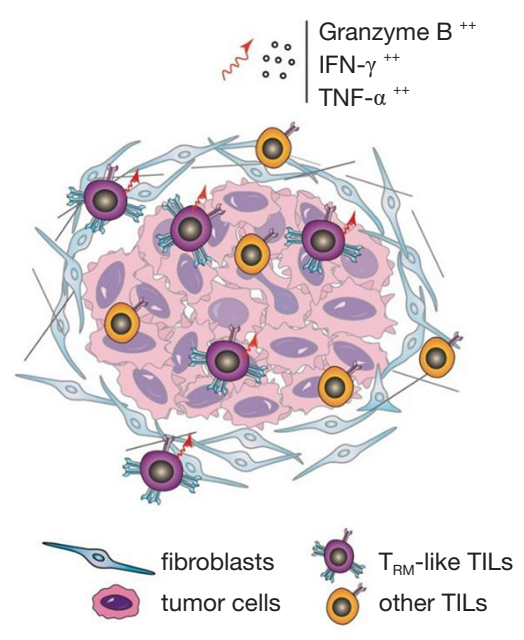

Figure $1 \mathrm{~T}_{\mathrm{RM}}$ in lung health and cancer. (A) In the healthy lung $\mathrm{CD} 4^{+}$and $\mathrm{CD} 8^{+} \mathrm{T}_{\mathrm{RM}}$ are located near the airways and in the alveolar space. $\mathrm{CD}^{+} \mathrm{T}_{\mathrm{RM}}$ form clusters closer to the airways while $\mathrm{CD} 8^{+} \mathrm{T}_{\mathrm{RM}}$ are more dispersed. Alveolar $\mathrm{T}_{\mathrm{RM}}$ have a low turn-over and replenish airway $\mathrm{T}_{\mathrm{RM}}$ that have a shorter half-life. (B) Tumor $\mathrm{T}_{\mathrm{RM}}$-like TILs are present in the cancer stroma and within the carcinoma, express higher levels of inhibitory molecules and secrete more inflammatory cytokines compared to healthy lung $T_{R M}$ and non $T_{R M}$-like TILs.

parenchyma and the airways (38). The 3D localization of $\mathrm{T}_{\mathrm{RM}}$ within bronchiolar and alveolar regions is still unclear, and how these locations may facilitate ready exposure to inhaled memorized antigens remains to be elucidated.

To maintain cellular homeostasis and prevent unnecessary immunopathology, cell death and proliferation of lung $\mathrm{T}_{\mathrm{RM}}$ are tightly regulated $(37,43)$. Particularly, mouse airways $\mathrm{T}_{\mathrm{RM}}$ have a relatively short half-life of 14 days $(39,40,43)$. Mouse studies have shown that alveolar $\mathrm{CD} 8^{+} \mathrm{T}_{\mathrm{RM}}$ will only form after exposure to an antigen within the lung and are maintained through a slow regenerative turn-over in the alveoli $(24,44)$. Alveolar $C D 8^{+} \mathrm{T}_{\mathrm{RM}}$ constantly replenish the pool of short-lived airways $\mathrm{CD} 8^{+} \mathrm{T}_{\mathrm{RM}}$ by migrating to the front line to respond to re-infection events (24) (Figure 1A). CXCL16 expressed by the airway epithelium appears to be the most prevalent chemokine responsible for the migration of CD $11 \mathrm{a}^{+} \mathrm{CXCR} 6^{+} \mathrm{CD}^{+} \mathrm{T}_{\mathrm{RM}}$ from the parenchyma to the airways where the expression of CD11a and CXCR6 is then downregulated $(23,24,40,45-47)$. Interestingly, there are some differences in the level of expression of CD103 and CD69 in $\mathrm{T}_{\mathrm{RM}}$ present in human lung airways or the parenchyma where the airways have more than a two-fold increase in the proportion of $\mathrm{CD}_{69^{+}} \mathrm{CD} 103^{+}$expressing $\mathrm{CD} 8^{+}$and $\mathrm{CD} 4^{+} \mathrm{T}$ cells compared with the alveolar parenchyma that has a higher proportion of $\mathrm{CD} 69^{+} \mathrm{CD} 103^{-}$cells (38). These results are reminiscent to what is observed in the human skin where the epidermis contains $\mathrm{CD} 69^{+} \mathrm{CD} 103^{+} \mathrm{CD} 4$ and $\mathrm{CD} 8 \mathrm{~T}$ cells, whereas the $\mathrm{CD} 69^{+} \mathrm{CD} 103^{-}$subset is more prevalent in the dermis for both CD4 and CD8 $\mathrm{T}_{\mathrm{RM}}$ (48). In the skin $\mathrm{CD} 69^{+} \mathrm{CD} 103^{+} \mathrm{T}_{\mathrm{RM}}$ express more effector cytokines such as IFN- $\gamma$ and TNF- $\alpha$ than $\mathrm{CD} 69^{+} \mathrm{CD} 103^{-} \mathrm{T}_{\mathrm{RM}}$ (48). It remains to be evaluated whether the same is true in the different subpopulations of lung $\mathrm{T}_{\mathrm{RM}}$.

Molecular mechanisms controlling tissue residency of lung $T_{R M}$ appear to be distinct from other tissue-specific $\mathrm{T}_{\mathrm{RM}}$. Mouse studies have shown that Hobit, Blimp1 and Runx3 are important mediators of tissue residency in the small intestine, liver, kidney and skin, by directly downregulating the expression of tissue egress receptor CCR7 and S1PR1 (49-51). However, detailed investigation of transcriptional programs regulating mouse lung $\mathrm{CD} 8^{+}$ $\mathrm{T}_{\mathrm{RM}}$ showed that Blimp1, but not Hobit, was required for their formation following influenza virus infection (52). In human lung, RUNX3 and HOBIT may be involved in the generation and/or maintenance of $\mathrm{CD}^{+} \mathrm{T}_{\mathrm{RM}}(38,50)$, although the expression of HOBIT appears lower in human lung $T_{R M}$ than mouse $T_{R M}$ (23), suggesting RUNX3 may be a common regulator of lung $\mathrm{T}_{\mathrm{RM}}$ in both species. Indeed, human and mouse $\mathrm{T}_{\mathrm{RM}}$ share a core transcriptional signature associated with RUNX3 expression (50). Runx3 also plays an important role in regulating TILs in a mouse 
model of melanoma, where Runx3-deficient T-cells fail to accumulate in the tumor, resulting in increased tumor growth. Conversely, overexpression of Runx 3 increased the recruitment of $\mathrm{CD}^{+} \mathrm{T}$ cells to the tumor and these TILs expressed a transcriptomic signature of tissue-residency (50). Further investigation will be necessary to specifically delineate the role of these distinct transcription factors in regulating $\mathrm{T}_{\mathrm{RM}}$ in healthy lung and lung tumors.

In early stage NSCLC, infiltration of $\mathrm{CD} 103^{+} \mathrm{CD} 8^{+}$ $\mathrm{T}_{\mathrm{RM}}$-like TILs in the tumors correlated with better patient survival (8). Interestingly, while a large proportion of these $\mathrm{T}_{\mathrm{RM}}$-like cells resided in the tumor stroma, high infiltration of $\mathrm{T}_{\mathrm{RM}}$-like TILs within the tumor was associated with an increase in the number of all TILs, irrelevant of the histological subtypes of NSCLC (Figure 1B). Those tumor-penetrating $\mathrm{T}_{\mathrm{RM}}$-like cells were more frequently observed in patients with a history of cigarettesmoking and were associated with better outcome (8). This observation in lung cancer was similar to endometrial adenocarcinoma where $\mathrm{CD} 103^{+} \mathrm{CD}^{+} \mathrm{T}$ cells were found in the carcinoma region but not in the stromal region, consistent with the role of CD103 in homing to epithelial cells (53). These studies highlight the importance of the spatial organization of the tumor microenvironment and suggest that in situ analysis will be critical to understand the role played by $\mathrm{T}_{\mathrm{RM}}$-like TILs in anti-tumor immunity.

In cancer progression, tumor cells utilize high levels of oxygen and nutrients leading to an aberrant metabolic state within the tumor-microenvironment (54). This nutrient deprivation may limit the lifespan and effector functions of lung $T_{R M}$ (37) suggesting that the function of $T_{R M^{-}}$ like TILs may also be impacted. Whether this nutrientdeprived environment limits the survival and function of $\mathrm{T}_{\mathrm{RM}}$-like TILs or drives a reprograming of their metabolic state promoting their survival and activity remains to be investigated.

\section{Lung $\mathbf{T}_{\mathrm{RM}}$ function in health and cancer}

In the healthy lung, $\mathrm{T}_{\mathrm{RM}}$ express a gene signature significantly different to peripheral blood circulating $\mathrm{T}$ cells, expressing genes encoding for effector molecules but also inhibitory regulators, indicating that these cells are poised for prompt response to infection, while maintaining immune tolerance (55). To rapidly recognize and respond to a large spectrum of invading pathogens, lung $T_{R M}$ express a large repertoire of TCR (26), with a higher TCR clonal diversity for $\mathrm{CD}^{+} \mathrm{T}_{\mathrm{RM}}$ compared with $C D 8^{+} \mathrm{T}_{\mathrm{RM}}$ (49). $\mathrm{T}_{\mathrm{RM}}$ act rapidly against pathogens due to their high expression of mRNAs encoding pro-inflammatory cytokine (IFN- $\gamma$, IL-17, IL-2, IL-10 and TNF- $\alpha$ ) and cytotoxic mediators (granzyme B, perforin) which would presumably prevent delays required by transcription $(23,26,37,38,49)$.

Similarly, $\mathrm{T}_{\mathrm{RM}}$-like TILs are primed for cytotoxic activity. The interaction of CD103 with tumor cells through e-cadherin triggers lytic granule polarization and exocytosis, promoting anti-tumor cytotoxicity $(30,56)$. Classification of early stage NSCLC tumors based on TIL expression of CD103 showed that in TIL-CD $103^{\text {hi }}$ tumors, TILs expressed higher levels of genes associated with proliferation (Ki67, cell cycle genes) and cytotoxicity (granzyme B, perforin, IFN- $\gamma$ ) compared with TIL-CD $103^{\text {lo }}$ tumors (5) (Figure 1B). Contrary to normal lung $\mathrm{T}_{\mathrm{RM}}$ that have a relatively quiescent phenotype $(57,58), \mathrm{CD} 103^{+}$ TILs were shown to be more proliferative than CD103TILs $(32,33)$. When $\mathrm{CD} 103^{+} \mathrm{CD} 8^{+}$cells were cultured in vitro in the presence of recombinant IL-2, cytotoxic degranulation was much more prominent in $\mathrm{CD} 103^{+}$cells compared with $\mathrm{CD} 103^{-}$cells isolated from the same tumor, as measured by granzyme B and CD107a expression (8). Further subdividing $\mathrm{CD}_{103}{ }^{+}$cells with $\mathrm{CD} 39^{+}$showed that $\mathrm{CD} 8^{+} \mathrm{CD} 39^{+} \mathrm{CD} 103^{+}$could kill autologous tumor cells in an in vitro co-culture assay three-times more efficiently than $\mathrm{CD}^{+} \mathrm{CD} 103^{+} \mathrm{CD} 39^{-}$cells in an MHC Class I-dependent manner, indicating that CD39 is an important marker to select for cytotoxic tumor-specific $\mathrm{T}_{\mathrm{RM}}$ like TILs (32).

IFN- $\gamma$ produced by $T_{R M}$ has been shown to increase the recruitment of circulating $\mathrm{T}$ cells to potentiate robust immune response to pathogens in infected tissue. IFN- $\gamma$ stimulates chemokine production by epithelial cells and increases the expression of adhesion molecules by the vasculature resulting in higher $\mathrm{T}$ cell infiltration $(59,60)$. Similarly, high production of IFN- $\gamma$ by tumor-specific $\mathrm{T}_{\mathrm{RM}}$-like cells may play a role in the recruitment of nonexhausted circulating $\mathrm{T}$ cells to the tumor. $\mathrm{CD} 103^{+} \mathrm{CD} 4^{+}$ TILs were found to express the highest levels of TNF- $\alpha$ and IFN- $\gamma$ upon CD3/CD28 stimulation compared with CD $103^{+} \mathrm{CD}^{+}$TILs or their lung $\mathrm{T}_{\mathrm{RM}}$ counterparts (6). These cytokines may contribute to the recruitment of functional $\mathrm{T}$ cells to the tumor site (Figure $2 A$ ). Indeed, Wu et al. recently showed that recruitment of peripheral $\mathrm{T}$ cells may be an important factor in response to immune checkpoint blockade (ICB) (13). The authors combined scTCR-sequencing and scRNA sequencing of T cells in tumors, unaffected adjacent tissue and blood samples and showed an expansion of $\mathrm{CD}^{+} \mathrm{T}$ cell clones in the blood 
A

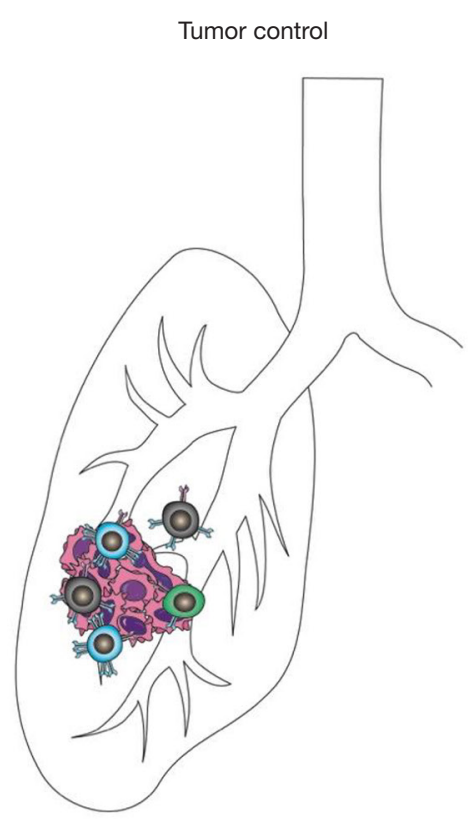

B

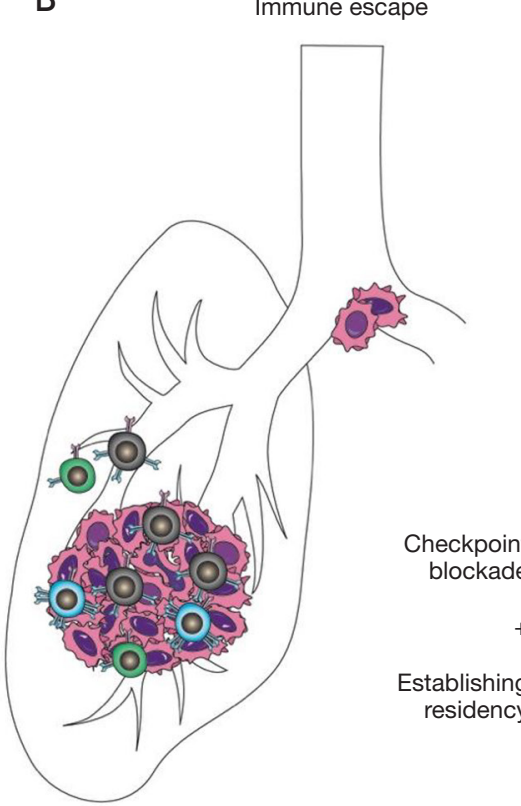

C

Immunotherapy-guided control

Tumor cells

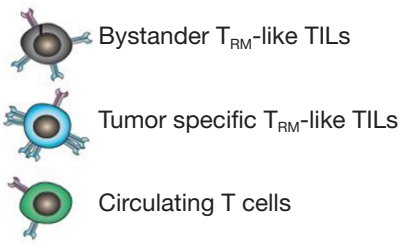

Figure 2 Harnessing $\mathrm{T}_{\mathrm{RM}}$ for cancer immunosurveillance at steady state and for long term tumor control. (A) Tumor neoantigen-specific $\mathrm{T}_{\mathrm{RM}}$-like TILs participate in maintaining the tumor-immune equilibrium to keep the tumor in check. (B) During immune escape, $\mathrm{T}_{\mathrm{RM}}$ guided surveillance is evaded through checkpoint molecules to allow for uncontrolled tumor cell growth and metastasis to pulmonary lymph nodes. (C) Checkpoint inhibitors, such as anti-PD-1, anti-CTLA4, anti-TIM3 and anti-LAG3, activate $\mathrm{T}_{\mathrm{RM}}$-like TILs (tumor-specific and bystander) and increase the recruitment of functional circulating T-cells to the tumor site. Combined with an understanding of factors driving long-term residency of tumor-specific $\mathrm{T}_{\mathrm{RM}}$ cells, longer-term local and systemic control of tumor growth could be achieved with appropriate personalized therapies.

that were also detected in the unaffected and tumor tissue. These data offer a novel paradigm in our understanding of anti-tumor immunity and $\mathrm{T}_{\mathrm{RM}}$ biology, where $\mathrm{CD} 103^{+} \mathrm{CD} 4^{+}$ tumor $\mathrm{T}_{\mathrm{RM}}$-like cells may mediate recruitment of nonexhausted peripheral $\mathrm{CD}^{+} \mathrm{T}$ cells to the tumor site. It remains to be seen how ICB act upon these $\mathrm{CD}^{+} \mathrm{T}_{\mathrm{RM}^{-}}$ like TILs, in parallel to reverting to a $\mathrm{T}$ cell exhaustion phenotype in $\mathrm{CD}^{+}$TILs.

\section{Implications for therapy}

Therapies that activate the anti-tumor response of cytotoxic $\mathrm{T}$ cells have shown great promises in the management of lung cancer patients. However, there is still a wide disparity in responses to these checkpoint immunotherapies, where only $20 \%$ of lung cancer patients show response with different degrees of duration $(61,62)$. The mechanisms behind a lack of response are still unclear, but recognition of a tumor-specific neoantigen by TILs is necessary for T cell mediated tumor cell destruction $(63,64)$. Lung cancerspecific $\mathrm{T}_{\mathrm{RM}}$ are ideally placed as targets for immunotherapy which aims to enhance tumor immunosurveillance. Their rapid response upon re-exposure to antigen compared to circulating memory cells, their residency within the lung and their close contact with epithelial cells at risk of malignant transformation ensures their molecular features 
and spatial environment are primed for tumor control. Although neoantigen-reactive $\mathrm{T}$ cells can be detected in the circulation (65), it is still unknown if subsets of neoantigen-specific $T$ cells become resident in the lung upon recognition of tumor neoantigens, likely due to the unsuitability of surface markers in tumors and the great heterogeneity of patients possessing bona fide tumorreactive $\mathrm{T}$ cells (66). Approaches to target cancer-specific $\mathrm{T}_{\mathrm{RM}}$ for lung cancer treatment center around three major strategies: targeting existing cancer-specific $T_{R M}$ that are being prevented from enacting anti-tumor immunity, harnessing bystander lung $\mathrm{T}_{\mathrm{RM}}$ for tumor immunity and activating cancer-specific $\mathrm{T}_{\mathrm{RM}}$ in tumors with inherently low immunogenicity.

Current FDA-approved ICB for NSCLC treatment include those blocking CTLA4, PD1 or its ligand PDL1 (67). PD-1, CTLA4 as well as TIM3 and LAG3 are co-inhibitory molecules expressed by lung $\mathrm{T}_{\mathrm{RM}}$ where they counteract the expression of activation molecules to limit inflammation-induced tissue damage and ensure immune tolerance $(23,55)$. Compared with their normal lung counterparts, tumor-infiltrating $\mathrm{T}_{\mathrm{RM}}$-like cells express higher levels of these co-inhibitory molecules. $\mathrm{CD}^{+} \mathrm{CD} 103^{+}$ tumor $\mathrm{T}_{\mathrm{RM}}$-like TILs express higher levels of TIM3, LAG3 and PD1 than $\mathrm{CD} 8^{+} \mathrm{CD} 103^{-}$TILs indicating that $\mathrm{T}_{\mathrm{RM}^{-}}$ like TILs are the likely targets of immune checkpoint inhibitors $(5,8,32,33$ ) (Figure $2 B$ ). Although patients with TIL-CD $103^{\text {hi }}$ lung tumors have a better overall survival outcome (5), this has not been linked to response to specific therapeutic strategies, including ICB. Exploring the exact balance of expression of co-inhibitory molecules on tumorspecific $T_{R M}$-like cells and bystander $T_{R M}$-like TILs will be necessary to evaluate these correlations. Nonetheless, in vitro studies showed that anti-PD1 or anti-PDL1 treatment was necessary to induce autologous tumor cell lysis by TILs and this effect was blocked in the presence of anti-CD103 antibody, indicating the critical role of $\mathrm{CD}_{103^{+}}$cells in restoring anti-tumor immunity upon ICB treatment (8). It is likely that current ICB therapies are effective both upon cancer-specific $\mathrm{T}_{\mathrm{RM}}$ and also by inducing the recruitment of $\mathrm{T}$ cells from the periphery $(5,8,13,32,68)$. Other immune checkpoints highly expressed by $\mathrm{T}_{\mathrm{RM}}$-like TILs are under investigation in clinical trials, including TIM3 and LAG3 (69), which may be effective under similar mechanisms to current ICBs. Consistently, CD $103^{+}$TILs in patients responding to anti-PD1 therapy expressed higher level of TIM3 than non-responders, indicating that inhibiting TIM3 may provide an additional therapeutic approach for tumors with primary or acquired resistance to anti-PD1 (33). Other sophisticated strategies include adoptive $T$ cell therapy, where neoantigen-specific $T$ cells are isolated and expanded from circulating $\mathrm{T}$ cells before re-infusion into the patient (70). A remaining question in the field is how long-term residency might be induced in cancer-specific $T_{R M}$ after successful immunotherapy for long term cancer immune-surveillance and control.

Recent studies have revealed a preponderance of bystander $T_{R M}$ within lung TILs that are reactive to unrelated epitopes (12). These cells are characterized by their lower expression of immune checkpoints compared to cancer-specific $\mathrm{T}_{\mathrm{RM}}$-like TILs, yet it is tempting to speculate they may still contribute to current ICB sensitivity by producing effector cytokines to support cancer-specific $\mathrm{T}_{\mathrm{RM}}$-like TILs or peripheral recruitment of effector $\mathrm{T}$ cells (Figure 2C). In contrast, bystander lung and other organ $\mathrm{T}_{\mathrm{RM}}$ could also contribute to immune-related adverse events (irAEs), common in patients who are sensitive to ICB (71). IrAEs include pneumonitis, dermatologic, gastrointestinal, endocrine and hepatic inflammatory events, indicating that ICBs induce augmentation of systemic immunity. Whether these effects are mediated differentially through circulating immune cells and/or tissue-specific $T_{\mathrm{RM}}$ remains to be explored. Use of genetically engineered mouse models will help understand the role of bystander and tumor-specific $\mathrm{T}_{\mathrm{RM}}$-like TILs in mediating anti-tumor immunity, and to determine how this response is accentuated by ICB. Tracing of circulating T-cells and their recruitment to the tumor site may also provide insights into the effect of ICB and $T_{\mathrm{RM}^{-}}$ like TILs in the recruitment of $\mathrm{T}$ cells from the circulation. Analysis of the phenotype and TCR repertoire of T-cell in bronchio-alveolar lavage fluid of patients who have developed pneumonitis as irAEs in response to ICB will also provide some clues on the mechanisms participating in the toxicity associated with ICB.

Tumor immunogenicity is necessary to induce an immune response. Immune escape mechanisms developed by tumor cells include loss of heterozygosity in major histocompatibility molecules I/II responsible for antigen presentation or reduced expression of neoantigens that can be recognized by $\mathrm{T}$ cell clones $(72,73)$. The vast heterogeneity in the TCR repertoire detected in early stage tumors correlates with the genetic heterogeneity of tumor cells and diversity in predicted neoantigens (74). However, best responses to ICB appear to come from T cells responding to neoantigens that are universally present in every tumor clone (75). It is tempting to speculate that 
the TILs recognizing a common neoantigen may have a $T_{R M}$-like phenotype, due to their tumor-retention and persistence in the tissue. Indeed, TCR sequencing of $\mathrm{CD}_{103^{+}}$and $\mathrm{CD}_{103^{-}}$lung cancer TILs demonstrated a much narrower TCR repertoire of $\mathrm{CD}_{103^{+}}{ }^{+}$TILs compared with CD103- TILs, indicating a clonal expansion of $\mathrm{T}_{\mathrm{RM}}{ }^{-}$ like TILs against a restricted number of tumor-specific neoantigens (33). Validating this observation could have significant therapeutic implications, notably to permit the use of compounds activating co-stimulatory molecules on $\mathrm{T}$ cells. Such strategies include antibodies targeting 41BB, OX40, CD27 and ICOS, for which progress in the clinic has been hampered by both immune side-effects and complex overlapping roles of these molecules in other tumor-infiltrating immune cells (76-78). However, activating these co-stimulatory molecules specifically within $\mathrm{T}_{\mathrm{RM}}$-like TILs may circumvent such issues. Other interventions to increase immunogenicity of tumors include oncolytic viruses in small cell lung cancer (79), dendritic cell vaccines, targeting myeloid-derived suppressor cells, chemotherapy and radiotherapy [reviewed in (80)]. The ability to induce residency of tumor-reactive $\mathrm{T}$ cells in these techniques should also be explored.

\section{Conclusions}

Tumor-specific $\mathrm{T}_{\mathrm{RM}}$-like cells could play an important role in early stage and advanced disease. $\mathrm{T}$ cell recognition of neoantigens and subsequent residency of $T_{R M}$-like TILs may help to prevent tumor relapse after successful treatment, and in late tumor evolution, $\mathrm{T}_{\mathrm{RM}}$-like TILs recognition of clonal neoantigens could prevent further metastatic dissemination (75). An emerging challenge in these strategies is immune evasion developed by tumors, including loss of MHC Class I expression and ability to present antigens. Further research into the mechanisms inducing tumor residency and immune evasion by tumors will enable personalized medicine for the immunotherapy era.

\section{Acknowledgments}

Funding: MLAL is supported by funding from the Viertel Foundation Senior Medical Research Fellowship. CLG is supported by funding from a NHMRC Early Career Fellowship (GNT1160963). This work is supported by a NHMRC Ideas Grant (GNT1182155), The Harry Secomb Trust, the Jenny Tatchell fund and by funds from the Operational Infrastructure Support Program provided by the Victorian Government and NHMRC IRIISS (Independent Research Institutes Infrastructure Support Scheme) Grant.

\section{Footnote}

Provenance and Peer Review: This article was commissioned by the Guest Editor (Daniel Steinfort) for the series "Lung cancer and the immune system" published in Translational Lung Cancer Research. The article was sent for external peer review organized by the Guest Editor and the editorial office.

Conflicts of Interest: All authors have completed the ICMJE uniform disclosure form (available at http://dx.doi. org/10.21037/tlcr-20-819). The series "Lung cancer and the immune system" was commissioned by the editorial office without any funding or sponsorship. CEW reports grants from Cure Cancer Australia/Cancer Australia, during the conduct of the study. MLAL reports grants from NHMRC Ideas Grant GNT1182155, grants from Viertel Senior Medical Researcher Fellowship, during the conduct of the study. The authors have no other conflicts of interest to declare.

Ethical Statement: The authors are accountable for all aspects of the work in ensuring that questions related to the accuracy or integrity of any part of the work are appropriately investigated and resolved.

Open Access Statement: This is an Open Access article distributed in accordance with the Creative Commons Attribution-NonCommercial-NoDerivs 4.0 International License (CC BY-NC-ND 4.0), which permits the noncommercial replication and distribution of the article with the strict proviso that no changes or edits are made and the original work is properly cited (including links to both the formal publication through the relevant DOI and the license). See: https://creativecommons.org/licenses/by-nc-nd/4.0/.

\section{References}

1. Steinert EM, Schenkel JM, Fraser KA, et al. Quantifying Memory CD8 T Cells Reveals Regionalization of Immunosurveillance. Cell 2015;161:737-49.

2. Wu T, Hu Y, Lee YT, et al. Lung-resident memory CD8 $\mathrm{T}$ cells (T RM) are indispensable for optimal cross- 
protection against pulmonary virus infection. J Leukoc Biol 2014;95:215-24.

3. Mueller SN, Gebhardt T, Carbone FR, et al. Memory T cell subsets, migration patterns, and tissue residence. Annu Rev Immunol 2013;31:137-61.

4. Schenkel JM, Fraser KA, Vezys V, et al. Sensing and alarm function of resident memory $\mathrm{CD}^{+} \mathrm{T}$ cells. Nat Immunol 2013;14:509-13.

5. Ganesan AP, Clarke J, Wood O, et al. Tissue-resident memory features are linked to the magnitude of cytotoxic $T$ cell responses in human lung cancer. Nat Immunol 2017;18:940-50.

6. Oja AE, Piet B, van der Zwan D, et al. Functional Heterogeneity of CD4+ Tumor-Infiltrating Lymphocytes With a Resident Memory Phenotype in NSCLC. Front Immunol 2018;9:2654.

7. Webb JR, Milne K, Watson P, et al. Tumor-Infiltrating Lymphocytes Expressing the Tissue Resident Memory Marker CD103 Are Associated with Increased Survival in High-Grade Serous Ovarian Cancer. Clin Cancer Res 2014;20:434-44.

8. Djenidi F, Adam J, Goubar A, et al. CD8 +CD103 +Tumor-Infiltrating Lymphocytes Are Tumor-Specific Tissue-Resident Memory T Cells and a Prognostic Factor for Survival in Lung Cancer Patients. J Immunol 2015;194:3475-86.

9. Wang ZQ, Milne K, Derocher H, et al. CD103 and Intratumoral Immune Response in Breast Cancer. Clin Cancer Res 2016;22:6290-7.

10. Park SL, Buzzai A, Rautela J, et al. Tissue-resident memory CD8+ T cells promote melanoma-immune equilibrium in skin. Nature 2019;565:366-71.

11. Lambrechts D, Wauters E, Boeckx B, et al. Phenotype molding of stromal cells in the lung tumor microenvironment. Nat Med 2018;24:1277-89.

12. Simoni Y, Becht E, Fehlings M, et al. Bystander CD8+ T cells are abundant and phenotypically distinct in human tumour infiltrates. Nature 2018;557:575-9.

13. Wu TD, Madireddi S, de Almeida PE, et al. Peripheral $T$ cell expansion predicts tumour infiltration and clinical response. Nature 2020;579:274-8.

14. Lian CG, Bueno EM, Granter SR, et al. Biomarker evaluation of face transplant rejection: association of donor T cells with target cell injury. Mod Pathol 2014;27:788-99.

15. Clark RA, Watanabe R, Teague JE, et al. Skin effector memory $\mathrm{T}$ cells do not recirculate and provide immune protection in alemtuzumab-treated CTCL patients. Sci Transl Med 2012;4:117ra7.
16. Szabo PA, Miron M, Farber DL. Location, location, location: Tissue resident memory $\mathrm{T}$ cells in mice and humans. Sci Immunol 2019;4:eaas9673.

17. Gebhardt T, Mackay LK. Local immunity by tissueresident CD8(+) memory T cells. Front Immunol 2012;3:340.

18. Sallusto F, Lenig D, Förster R, et al. Two subsets of memory $\mathrm{T}$ lymphocytes with distinct homing potentials and effector functions. Nature 1999;401:708-12.

19. Beura LK, Wijeyesinghe S, Thompson EA, et al. T Cells in Nonlymphoid Tissues Give Rise to Lymph-NodeResident Memory T Cells. Immunity 2018;48:327-38.e5.

20. Skon CN, Lee JY, Anderson KG, et al. Transcriptional downregulation of S1pr1 is required for the establishment of resident memory CD8+ T cells. Nat Immunol 2013;14:1285-93.

21. Mokrani M, Klibi J, Bluteau D, et al. Smad and NFAT pathways cooperate to induce CD103 expression in human CD8 T lymphocytes. J Immunol 2014;192:2471-9.

22. Lee YT, Suarez-Ramirez JE, Wu T, et al. Environmental and antigen receptor-derived signals support sustained surveillance of the lungs by pathogen-specific cytotoxic $\mathrm{T}$ lymphocytes. J Virol 2011;85:4085-94.

23. Kumar BV, Ma W, Miron M, et al. Human TissueResident Memory T Cells Are Defined by Core Transcriptional and Functional Signatures in Lymphoid and Mucosal Sites. Cell Rep 2017;20:2921-34.

24. Takamura S, Kato S, Motozono C, et al. Interstitialresident memory CD8+T cells sustain frontline epithelial memory in the lung. J Exp Med 2019;216:2736-47.

25. Takamura S, Yagi H, Hakata Y, et al. Specific niches for lung-resident memory CD8+ T cells at the site of tissue regeneration enable CD69-independent maintenance. J Exp Med 2016;213:3057-73.

26. Purwar R, Campbell J, Murphy G, et al. Resident Memory T Cells (TRM) Are Abundant in Human Lung: Diversity, Function, and Antigen Specificity. Proost P, editor. PLoS One 2011;6:e16245-9.

27. Teijaro JR, Turner D, Pham Q, et al. Cutting edge: Tissueretentive lung memory CD4 $\mathrm{T}$ cells mediate optimal protection to respiratory virus infection. J Immunol 2011;187:5510-4.

28. Turner DL, Bickham KL, Thome JJ, et al. Lung niches for the generation and maintenance of tissue-resident memory T cells. Mucosal Immunol 2014;7:501-10.

29. Galkina E. Preferential migration of effector CD8+ T cells into the interstitium of the normal lung. J Clin Invest 2005;115:3473-83. 
30. Le Floc'h A, Jalil A, Vergnon I, et al. $\alpha \mathrm{E} \beta 7$ integrin interaction with E-cadherin promotes antitumor CTL activity by triggering lytic granule polarization and exocytosis. J Exp Med 2007;204:559-70.

31. Gebhardt T, Palendira U, Tscharke DC, et al. Tissueresident memory $T$ cells in tissue homeostasis, persistent infection, and cancer surveillance. Immunol Rev 2018;283:54-76.

32. Duhen T, Duhen R, Montler R, et al. Co-expression of CD39 and CD103 identifies tumor-reactive CD8 T cells in human solid tumors. Nat Commun 2018;9:2724.

33. Clarke J, Panwar B, Madrigal A, et al. Single-cell transcriptomic analysis of tissue-resident memory $\mathrm{T}$ cells in human lung cancer. J Exp Med 2019;216:2128-49.

34. Lavin Y, Kobayashi S, Leader A, et al. Innate Immune Landscape in Early Lung Adenocarcinoma by Paired Single-Cell Analyses. Cell 2017;169:750-65.e17.

35. Stoeckius M, Hafemeister C, Stephenson W, et al. Simultaneous epitope and transcriptome measurement in single cells. Nat Methods 2017;14:865-8.

36. Keren L, Bosse M, Marquez D, et al. A Structured TumorImmune Microenvironment in Triple Negative Breast Cancer Revealed by Multiplexed Ion Beam Imaging. Cell 2018;174:1373-87.e19.

37. Hayward SL, Scharer CD, Cartwright EK, et al. Environmental cues regulate epigenetic reprogramming of airway-resident memory CD8+ T cells. Nat Immunol 2020;21:309-20.

38. Snyder ME, Finlayson MO, Connors TJ, et al. Generation and persistence of human tissue-resident memory $\mathrm{T}$ cells in lung transplantation. Sci Immunol 2019;4:eaav5581.

39. McMaster SR, Wilson JJ, Wang H, et al. AirwayResident Memory CD8 T Cells Provide Antigen-Specific Protection against Respiratory Virus Challenge through Rapid IFN- $\gamma$ Production. J Immunol 2015;195:203-9.

40. Ely KH, Cookenham T, Roberts AD, et al. Memory T Cell Populations in the Lung Airways Are Maintained by Continual Recruitment. J Immunol 2006;176:537-43.

41. Kumar PA, Hu Y, Yamamoto Y, et al. Distal Airway Stem Cells Yield Alveoli In Vitro and during Lung Regeneration following H1N1 Influenza Infection. Cell 2011;147:525-38.

42. Vaughan AE, Brumwell AN, Xi Y, et al. Lineage-negative progenitors mobilize to regenerate lung epithelium after major injury. Nature 2015;517:621-5.

43. Slütter B, Van Braeckel-Budimir N, Abboud G, et al. Dynamics of influenza-induced lung-resident memory $T$ cells underlie waning heterosubtypic immunity. Sci
Immunol 2017;2:eaag2031-26.

44. McMaster SR, Wein AN, Dunbar PR, et al. Pulmonary antigen encounter regulates the establishment of tissueresident CD8 memory T cells in the lung airways and parenchyma. Mucosal Immunol 2018;11:1071-8.

45. Day C, Patel R, Guillen C, et al. The chemokine CXCL16 is highly and constitutively expressed by human bronchial epithelial cells. Exp Lung Res 2009;35:272-83.

46. Wein AN, McMaster SR, Takamura S, et al. CXCR6 regulates localization of tissue-resident memory CD8 T cells to the airways. J Exp Med 2019;216:2748-62.

47. Zaid A, Hor JL, Christo SN, et al. Chemokine ReceptorDependent Control of Skin Tissue-Resident Memory T Cell Formation. J Immunol 2017;199:2451-9.

48. Watanabe R, Gehad A, Yang C, et al. Human skin is protected by four functionally and phenotypically discrete populations of resident and recirculating memory $\mathrm{T}$ cells. Sci Transl Med 2015;7:279ra39-9.

49. Kumar BV, Connors TJ, Farber DL. Human T Cell Development, Localization, and Function throughout Life. Immunity 2018;48:202-13.

50. Milner JJ, Toma C, Yu B, et al. Runx3 programs CD8+ $T$ cell residency in non-lymphoid tissues and tumours. Nature 2017;552:253-7.

51. Mackay LK, Minnich M, Kragten NAM, et al. Hobit and Blimp1 instruct a universal transcriptional program of tissue residency in lymphocytes. Science 2016;352:459-63.

52. Behr FM, Kragten NAM, Wesselink TH, et al. Blimp-1 Rather Than Hobit Drives the Formation of TissueResident Memory CD8+ T Cells in the Lungs. Front Immunol 2019;10:400.

53. Workel HH, Komdeur FL, Wouters MCA, et al. CD103 defines intraepithelial CD8+ PD1+ tumour-infiltrating lymphocytes of prognostic significance in endometrial adenocarcinoma. Eur J Cancer 2016;60:1-11.

54. Gupta S, Roy A, Dwarakanath BS. Metabolic Cooperation and Competition in the Tumor Microenvironment: Implications for Therapy. Front Oncol 2017;7:68.

55. Hombrink P, Helbig C, Backer RA, et al. Programs for the persistence, vigilance and control of human CD8+ lungresident memory T cells. Nat Immunol 2016;17:1467-78.

56. Franciszkiewicz K, Le Floc'h A, Boutet M, et al. CD103 or LFA-1 Engagement at the Immune Synapse between Cytotoxic T Cells and Tumor Cells Promotes Maturation and Regulates T-cell Effector Functions. Cancer Res 2013;73:617-28.

57. Wakim LM, Woodward-Davis A, Liu R, et al. The molecular signature of tissue resident memory CD8 $\mathrm{T}$ cells isolated 
from the brain. J Immunol 2012;189:3462-71.

58. Mackay LK, Rahimpour A, Ma JZ, et al. The developmental pathway for CD103(+)CD8+ tissue-resident memory T cells of skin. Nat Immunol 2013;14:1294-301.

59. Ariotti S, Hogenbirk MA, Dijkgraaf FE, et al. T cell memory. Skin-resident memory $\mathrm{CD} 8^{+} \mathrm{T}$ cells trigger a state of tissue-wide pathogen alert. Science 2014;346:101-5.

60. Schenkel JM, Fraser KA, Beura LK, et al. T cell memory. Resident memory CD8 T cells trigger protective innate and adaptive immune responses. Science 2014;346:98-101.

61. Rizvi H, Sanchez-Vega F, La K, et al. Molecular Determinants of Response to Anti-Programmed Cell Death (PD)-1 and Anti-Programmed Death-Ligand 1 (PD-L1) Blockade in Patients With Non-Small-Cell Lung Cancer Profiled With Targeted Next-Generation Sequencing. J Clin Oncol 2018;36:633-41.

62. Herbst RS, Garon EB, Kim DW, et al. Long-Term Outcomes and Retreatment Among Patients With Previously Treated, Programmed Death-Ligand 1Positive, Advanced Non-Small-Cell Lung Cancer in the KEYNOTE-010 Study. J Clin Oncol 2020;38:1580-90.

63. Datta M, Coussens LM, Nishikawa H, et al. Reprogramming the Tumor Microenvironment to Improve Immunotherapy: Emerging Strategies and Combination Therapies. Am Soc Clin Oncol Educ Book 2019;(39):165-74.

64. Kalbasi A, Ribas A. Tumour-intrinsic resistance to immune checkpoint blockade. Nat Rev Immunol 2020;20:25-39.

65. Peng S, Zaretsky JM, Ng AHC, et al. Sensitive Detection and Analysis of Neoantigen-Specific T Cell Populations from Tumors and Blood. Cell Rep 2019;28:2728-38.e7.

66. Ribas A, Wolchok JD. Cancer immunotherapy using checkpoint blockade. Science 2018;359:1350-5.

67. Ready N, Hellmann MD, Awad MM, et al. First-Line Nivolumab Plus Ipilimumab in Advanced Non-SmallCell Lung Cancer (CheckMate 568): Outcomes by Programmed Death Ligand 1 and Tumor Mutational Burden as Biomarkers. J Clin Oncol 2019;37:992-1000.

68. Li H, van der Leun AM, Yofe I, et al. Dysfunctional CD8 T Cells Form a Proliferative, Dynamically Regulated Compartment within Human Melanoma. Cell 2019;176:775-89.e18.

69. Anderson AC, Joller N, Kuchroo VK. Lag-3, Tim-3, and TIGIT: Co-inhibitory Receptors with Specialized Functions in Immune Regulation. Immunity
2016;44:989-1004.

70. Robertson J, Salm M, Dangl M. Adoptive cell therapy with tumour-infiltrating lymphocytes: the emerging importance of clonal neoantigen targets for next-generation products in non-small cell lung cancer. Immuno-Oncology Technology 2019;3:1-7.

71. Postow MA, Callahan MK, Wolchok JD. Immune Checkpoint Blockade in Cancer Therapy. J Clin Oncol 2015;33:1974-82.

72. McGranahan N, Rosenthal R, Hiley CT, et al. AlleleSpecific HLA Loss and Immune Escape in Lung Cancer Evolution. Cell 2017;171:1259-71.e11.

73. Rosenthal R, Cadieux EL, Salgado R, et al. Neoantigendirected immune escape in lung cancer evolution. Nature 2019;567:479-85.

74. Reuben A, Gittelman R, Gao J, et al. TCR Repertoire Intratumor Heterogeneity in Localized Lung Adenocarcinomas: An Association with Predicted Neoantigen Heterogeneity and Postsurgical Recurrence. Cancer Discov 2017;7:1088-97.

75. McGranahan N, Furness AJS, Rosenthal R, et al. Clonal neoantigens elicit $\mathrm{T}$ cell immunoreactivity and sensitivity to immune checkpoint blockade. Science 2016;351:1463-9.

76. Sanmamed MF, Etxeberría I, Otano I, et al. Twists and turns to translating 4-1BB cancer immunotherapy. Sci Transl Med 2019;11:eaax4738.

77. Buchan SL, Rogel A, Al-Shamkhani A. The immunobiology of CD27 and OX40 and their potential as targets for cancer immunotherapy. Blood 2018;131:39-48.

78. Amatore F, Gorvel L, Olive D. Inducible Co-Stimulator (ICOS) as a potential therapeutic target for anti-cancer therapy. Expert Opin Ther Targets 2018;22:343-51.

79. Kellish P, Shabashvili D, Rahman MM, et al. Oncolytic virotherapy for small-cell lung cancer induces immune infiltration and prolongs survival. J Clin Invest 2019;129:2279-92.

80. Sharma P, Hu-Lieskovan S, Wargo JA, et al. Primary, Adaptive, and Acquired Resistance to Cancer Immunotherapy. Cell 2017;168:707-23.

Cite this article as: Marceaux C, Weeden CE, Gordon CL, Asselin-Labat ML. Holding our breath: the promise of tissueresident memory $\mathrm{T}$ cells in lung cancer. Transl Cancer Res 2021;10(6):2819-2829. doi: 10.21037/tlcr-20-819 